\title{
Clinical practice guidelines for the medical management of nonhospitalized ulcerative colitis: The patient perspective
}

\author{
A Hillary Steinhart MD MSc FRCPC ${ }^{1}$, Aida Fernandes BSc MBA ${ }^{2}$
}

\begin{abstract}
AH Steinhart, A Fernandes. Clinical practice guidelines for the medical management of nonhospitalized ulcerative colitis: The patient perspective. Can J Gastroenterol Hepatol 2015;29(6):294-296.
\end{abstract}

A series of clinical practice guidelines were recently developed by the Canadian Association of Gastroenterology (CAG) to provide clinicians with recommendations for the medical management of nonhospitalized ulcerative colitis (UC) patients. These guidelines were developed, reviewed and agreed on by expert clinicians and methodologists. Following the finalization of the guidelines, a group of patients with UC as well as several inflammatory bowel disease clinicians, were brought together for a half-day workshop to provide feedback from the patient perspective. At the workshop, the guideline development process was described and the guidelines were reviewed to ensure comprehension. Patients then had the opportunity to provide their insight to the relevance of the guideline development process and the content of the guidelines as it related to their personal experiences with UC. The patient group believed that, although the new guidelines will be a tremendous resource for the health care provider community, a more 'layfriendly' version would better facilitate dialogue between patients and their health care practitioners. The importance of the patient/physician relationship is paramount when making decisions regarding treatment plans, in which patient preferences play a key role in determining the most appropriate therapy and dosing regimen, which, in turn, impact the likelihood of adherence to the treatment plan. It was also believed that quality of life issues were not fully addressed in the guidelines. Much could be learned from shared experiences and coping strategies that would empower patients to take charge of their health and become equal partners with their care providers.

Key Words: Consensus conference; Drug therapy; Inflammatory bowel disease; Patient perspective; Practice guidelines; Ulcerative colitis

\author{
Directives cliniques pour la prise en charge \\ médicale de la colite ulcéreuse ambulatoire : \\ le point de vue du patient
}

L'Association canadienne de gastroentérologie (ACG) a récemment publié pour les cliniciens une série de directives cliniques qui contiennent des recommandations sur la prise en charge des patients non hospitalisés atteints de colite ulcéreuse (CU). Ce sont des cliniciens experts et des méthodologues qui les ont élaborées, révisées et adoptées. Une fois les directives terminées, un groupe de patients atteints de CU et plusieurs cliniciens spécialisés en maladies inflammatoires de l'intestin se sont réunis dans le cadre d'un atelier d'une demi-journée pour connaître l'avis des patients. Le processus d'élaboration des directives a été expliqué et les directives ont été passées en revue en début d'atelier, afin de s'assurer que le tout sait bien compris. Les patients ont ensuite eu l'occasion de donner leur point de vue sur la pertinence du processus d'élaboration des directives et de leur contenu par rapport à leurs expériences personnelles de la CU. Le groupe de patients trouvait que, même si les nouvelles directives représenteront une excellente ressource pour les dispensateurs de soins, une version vulgarisée faciliterait le dialogue avec les patients. La relation entre le patient et son médecin est d'une importance capitale lors de la prise de décisions au sujet du plan de traitement, car les préférences des patients jouent un rôle essentiel pour bien déterminer le choix du traitement et la posologie les mieux adaptés. Ces préférences influent sur la probabilité d'adhésion au traitement. Les patients trouvaient également que les questions relatives à la qualité de vie n'étaient pas pleinement abordées. Il y a beaucoup à apprendre des expériences partagées et des stratégies d'adaptation qui inciteraient les patients à prendre leur santé en charge et à devenir des partenaires sur un pied d'égalité avec leurs dispensateurs de soins.
Clinical practice guidelines are an invaluable resource for health care professionals, providing both an overview of a clinical problem and recommendations on the best approaches for optimal management. In contrast to accepted standards of care, guidelines are developed with the flexibility to be responsive to individual patient needs, as well as new developments in medical research and practice. Clinical practice guidelines encourage the delivery of standardized care across a given jurisdiction so that all patients with the same or similar health problems receive consistent, high-quality care, regardless of variables such as physician experience, access (rural versus urban) or socioeconomic status.

Inflammatory bowel disease, consisting of the two main forms of ulcerative colitis and Crohn disease, represents a significant health and economic burden, particularly in northern countries of the world such as Canada. Ulcerative colitis is the most common of these diseases, with approximately 4500 cases diagnosed each year in Canada, and an estimated 104,000 Canadians living with the disease based on a report published in 2012 (1). Ulcerative colitis is a chronic disease of unknown cause that can develop at any age, with peak incidence between 15 and 25 years of age, and is characterized by periods of remission and flares with symptoms that include bloody diarrhea, urgency, tenesmus and abdominal pain. If uncontrolled, the disease can have significant adverse effects on a person's health, social, psychosocial and economic well-being (1).

Although options for the clinical management of ulcerative colitis continue to expand, with improvements in early diagnosis and the development of a wide choice of available drug preparations and dosing regimens, the unpredictable and chronic course of the disease remains a challenge in efforts to achieve life-long remission (2). There are several perceived inconsistencies in the standards of care across the country, including variability in support for patients and caregivers, and equitable access to new drug therapies. In 2014, the Canadian gastroenterology community, through the Canadian Association of Gastroenterology (CAG), undertook the initiative to

${ }^{1}$ Department of Medicine, University of Toronto and Mount Sinai Hospital Inflammatory Bowel Disease Centre and the Zane Cohen Digestive Diseases

Clinical Research Centre, Toronto, Ontario; ${ }^{2}$ Crohn's and Colitis Canada

Correspondence: Dr A Hillary Steinhart, Division of Gastroenterology, Mount Sinai Hospital, Room 445, 600 University Avenue, Toronto,

Ontario M5G 1X5. Fax 416-586-5121, e-mail hsteinhart@mtsinai.on.ca

Received for publication March 19, 2015. Accepted March 23, 2015 
address this need and began a process to develop clinical practice guidelines to optimize the management of ulcerative colitis in nonhospitalized patients in the Canadian context. These guidelines will complement the 2011 Canadian guidelines for the management of severe, hospitalized cases of ulcerative colitis (3), as well as similar guidelines developed in the United States (2010 Ulcerative Colitis Practice Guidelines in Adults [4]) and in the United Kingdom (2013 National Institute for Health and Care Excellence clinical guidelines for the management of ulcerative colitis in adults, children and young people [5]).

\section{GUIDELINE DEVELOPMENT PROCESS}

The CAG Clinical Affairs Committee created a guideline development committee with two co-chairs, a steering committee and a group of 23 voting participants, including academic and community gastroenterologists with expertise in various aspects of ulcerative colitis management, a pharmacist, and a nonvoting facilitator. The steering committee developed initial drafts of treatment statements and several expert working groups were tasked with undertaking a systematic review of the current literature, and developing and revising these treatment statements. Several months later, following two successive web-based iterations of review and revision, the group reconvened for a two-day consensus meeting to vote on the statements, finalize the guidelines and allocate Grading of Recommendation Assessment, Development and Evaluation (GRADE) assessments for each statement (6). Finally, 34 consensus statements were agreed on, covering traditional therapies (5-aminosalicylic acid, corticosteroids, immunosuppressants, anti-tumour necrosis factor drugs), as well as more experimental agents, such as new biologics, fecal microbial transplants and probiotics. The full document entitled "Clinical practice guidelines for the medical management of non-hospitalized ulcerative colitis: The Toronto consensus" has recently been published (7). The new guidelines will be an important resource for health care practitioners, provincial health care funders and private health care insurers, as well as patients and their families, and will provide benchmarks for quality improvement initiatives aimed at providing consistent and equitable access to care across Canada. It is anticipated that they will represent a 'living' document available for update in response to the emergence of new knowledge, therapies and treatment protocols.

\section{THE PATIENT PERSPECTIVE}

In preparation for the public release of the new guidelines, Crohn's and Colitis Canada (CCC), with the collaboration of CAG, assembled a small focus group of heath care professionals and ulcerative colitis patients to review the guidelines and provide input on their relevance and potential impact from the patient perspective. During the half-day meeting, the group reviewed the consensus process, the terminology and definitions used in the guideline development, and the 34 consensus statements that had been agreed on and graded according to the strength of the recommendation and the quality of the supporting evidence.

\section{OVERALL IMPRESSIONS}

Patients and health practitioners were impressed that the Canadian gastroenterology community had voluntarily committed so much time and effort to the development of the consensus guidelines and believed that it aptly reflected the dedication of the gastroenterology, clinical and research community and their level of support for their patients. This effort should not be underestimated and could be an important factor when gaining acceptance of the guidelines among the Canadian ulcerative colitis patient community.

The group believed that the new guidelines would be an important addition to currently available information and represented a significant step forward in the management of the disease, but expressed some concern about discrepancies between some of the recommendations in these guidelines and those in similar international guidelines. It was suggested that these differences could be referred to and explained to avoid confusion. For purposes of clarity, it was also suggested that the patient demographic should be better defined because the guidelines may need to be amended for pediatric patients or specific groups such as pregnant women.

\section{ENHANCING PATIENT ENGAGEMENT}

Although the group was truly appreciative of the effort invested into creating the guidelines, there was agreement that for them to be of practical value to patients and their caregivers a 'lay-friendly' version, using terminology and language that is more widely understood, would be a significant asset. The scientific and regulatory language used in the guidelines is intended for experienced clinicians who understand the terminologies used, including the definitions of mild, moderate and severe disease and the statement grading system. However, patients may have a different understanding of these definitions, potentially leading to confusion and compromising the accessibility of the document, not just for patients and their families, but also for clinicians lacking experience in the management of ulcerative colitis. Because all physicians are not equally familiar with the disease and not all patients are well informed, a document written in plain language, appropriate for facilitating dialogue and guiding discussions between patients and their health care providers in a standardized fashion would be a great asset. An example is the United Kingdom ulcerative colitis guidelines produced by the National Institute for Health and Care Excellence, which are written and presented in a highly logical, easy to interpret format that is clearly geared toward patient engagement (8). The patients believed very strongly that, going forward, patient involvement in the development of clinical practice guidelines - for any health condition - should be an essential component to fully incorporate the patient experience, a perspective that is increasingly gaining traction among the broader Canadian health care community.

\section{PATIENT ADHERENCE TO TREATMENT PLANS}

The focus group placed great emphasis on the importance of the doctor/ patient relationship for the successful management of ulcerative colitis. This is particularly important for managing patient adherence with treatment plans, in which nonadherence is frequently a contributing factor in relapse. Most people understand acute illness; however, when first diagnosed with ulcerative colitis, patients may not immediately appreciate that this is a chronic condition potentially requiring a lifetime of maintenance therapy. Once in remission, patients may not see the need to continue taking drugs, which they fear may have side effects or negative long-term consequences. Without open and honest communication between patient and health care practitioner, patients will sometimes not be entirely honest about their level of treatment adherence, not realizing that frequent relapses may make future responses more difficult to achieve with therapies that were previously effective. They may also not fully recognize the potential need for surgery if medical therapy becomes ineffective due to lack of adherence.

The route of drug administration may also play a role in patient adherence. For example, the 5-aminosalicylic acid-containing therapies are highly effective in inducing long-term remission and have proven to be safe for extended periods. However, there is a significant difference, from the patient perspective, with regard to route of drug administration, whether oral or rectal. Not surprisingly, patients generally prefer oral administration and, in this instance, quality of life issues often trump doctor's recommendations, even if the evidence suggests that rectal therapy is superior for maintenance therapy in some situations. This is an area in which a dialogue that includes a thorough explanation of the current guidelines and reasons supporting them could play an important role in influencing adherence. This is particularly true for young patients in whom the stigma associated with the disease can be significant.

Dosing is another issue that would benefit from more clarity and discussion. There is some disagreement about the frequency of drug 
delivery necessary to induce and maintain remission, ranging from once per day to three or four times per day, depending on the medication and disease activity. This often leads to 'dose creep', in which busy patients either forget to take their second and third dose, or decide to arbitrarily reduce the number of pills because they feel better. Additionally, economic factors can come into play because many of the drugs, especially the newer biologic therapies, are expensive and, therefore, more drugs means increased cost. Compounding this problem is the fact that some drugs are available in several different formulations, making it challenging to compare medications, recommended doses and costs.

Evaluation of treatment response is also an area of concern for patients, especially for therapies with known adverse effects such as corticosteroids. Patients need to be made aware of the risks of reducing their medication before being clinically evaluated for a response. Individuals with ulcerative colitis tend to become resilient in coping with their disease and may ignore signs of relapse in the hope that things will improve spontaneously, not realizing that the sicker they become, the longer the recovery time is likely to be. In addition, a patient's definition of 'normal' is often different from a doctor's and patients do not necessarily understand the clinical definitions of mild, moderate and severe disease in the same way, tending to assume that if they are functioning then their disease must be mild. This is an example of an area in which 'lay friendly' guidelines would be particularly useful for facilitating doctor/patient discussions. For example, the end points being strived for by physicians, namely achieving a status free from inflammation, are complicated by the fact that symptom reporting by patients, although important, may not align with more objective assessments such as endoscopy findings.

Overall, the group believed that many of the challenges related to adherence to treatment plans could be addressed in a 'lay-friendly' version of the guidelines that could be used to facilitate a two-way dialogue between patient and health care practitioner. The key objective would be to establish a common understanding of the terminologies used, and the risks and benefits associated with various treatment options.

\section{DISEASE MONITORING}

The group suggested that additional patient guidelines on the recommended frequency of follow-up colonoscopy in symptom-free ulcerative colitis patients in remission would be useful. Due to the elevated risk for colorectal cancer in ulcerative colitis patients, regular screening is recommended by endoscopy or colonoscopy, but practices with respect to the actual frequency of monitoring differ among practitioners and institutions, with some recommending a colonoscopy every year in patients who have had disease for $>10$ years. Unfortunately, colonoscopy is an invasive and potentially uncomfortable procedure, and the preparation required tends to be inconvenient and, at best, unpleasant. Colonoscopy is also associated with rare, but potentially serious complications. Consensus is needed as to the best approach for the long-term monitoring of patients who otherwise feel well. Fortunately, a less-invasive marker of disease activity, fecal calprotectin, has recently become available for clinical evaluation and implementation. This stool test correlates well with the presence of endoscopically observed inflammation.

\section{EXPERIMENTAL THERAPIES}

The focus group generally agreed with the recommendations in the guidelines that experimental treatments, such as fecal transplants and probiotics, are currently best evaluated in a clinical trial(s) setting, but believed that more information on new treatments and approaches would be beneficial. Enthusiastic support was expressed for more clinical trials to assess the efficacy of potential new therapies in a timely fashion. The group believed that the guidelines should empower patients by including a focus on overall quality of life issues and coping strategies for people living with ulcerative colitis. Examples include environmental factors, stress management strategies and dietary methods of symptom management, especially during active phases of the disease where certain foods may increase symptoms. Also, because some patients work closely with naturopaths for symptom management, patients should be encouraged to discuss additional/alternative therapies they may be using with their health practitioners to avoid potentially adverse interactions.

\section{SUMMARY}

The 2015 "Clinical practice guidelines for the medical management of non-hospitalized ulcerative colitis: The Toronto consesnsus" were enthusiastically received by a small focus group of ulcerative colitis patients and health practitioners, convened by CCC in partnership with CAG. The group fully appreciated the amount of work and effort invested into preparing the guidelines and recognized the dedication and commitment of the group of gastroenterologists who assumed responsibility for the task. Because patient engagement is becoming increasingly important in the design and delivery of health care, it was suggested that future endeavours may benefit from the inclusion of the patient experience during the guideline development process.

As written, the new guidelines will be a tremendous resource for ulcerative colitis experts working in the field. However, it was believed that to better facilitate dialogue between patients and their health care practitioners, a 'lay-friendly' version would be a significant asset. The patient/physician relationship is of paramount importance when making decisions on treatment plans, in which patient preferences plays a key role in determining the most appropriate therapy and dosing regimen which, in turn, impact the likelihood of adherence to the plan. In terms of the patient experience, one element that was noted as missing from the guidelines was mention of overall quality of life issues for ulcerative colitis patients. It was agreed that much could be learned from shared experiences and coping strategies, and that opportunities to share experiences would empower patients to take charge of their health and become equal partners with their care providers.

ACKNOWLEDGEMENTS: The authors thank the following patients and health care practitioners who participated in the meeting and provided important feedback on the patient perspective with respect to the guidelines: Naazish Bashir, Ron De Paola, Joan Heatherington, Carol Hughes, Karen Kroeker, Kevin Ram, Walter Reinisch. The authors also thank Judith Bray who coordinated and facilitated the workshop and provided valuable assistance in summarizing the discussions on which this publication are based.

\section{REFERENCES}

1. Crohn's and Colitis Foundation of Canada. The Impact of Inflammatory Bowel Disease in Canada, 2012.

$<$ www.isupportibd.ca/pdf/ccfc-ibd-impact-report-2012.pdf> (Accessed February 16, 2015).

2. Danese $S$. New therapies for inflammatory bowel disease: From the bench to the bedside. Gut 2012;61:918-32.

3. Bitton A, Buie D, Enns R, et al. Treatment of hospitalized adult patients with severe ulcerative colitis: Toronto consensus statements. Am J Gastroenterol 2012;107:179-94.

4. Kornbluth A, Sachar DB. Ulcerative colitis practice guidelines in adults: American College Of Gastroenterology, Practice Parameters Committee. Am J Gastroenterol 2010;105:501-23.

5. Stenke E, Hussey S. Ulcerative colitis: Management in adults, children and young people (NICE Clinical Guideline CG166). Arch Dis Child Educ Pract Ed 2014;99:194-7.

6. Guyatt GH, Oxman AD, Vist GE et al. GRADE: An emerging consensus on rating quality of evidence and strength of recommendations. BMJ 2008;336:924-6.

7. Bressler B, Marshall JK, Bernstein CN et al. Clinical practice guidelines for the medical management of nonhospitalized ulcerative colitis: The Toronto consensus. Gastroenterology 2015;148:1035-58.e3.

8. National Clinical Guideline Centre < www.nice.org.uk/guidance/ cg166/evidence/cg166-ulcerative-colitis-full-guideline3> (Accessed March 12, 2015). 


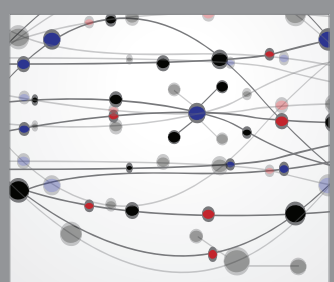

The Scientific World Journal
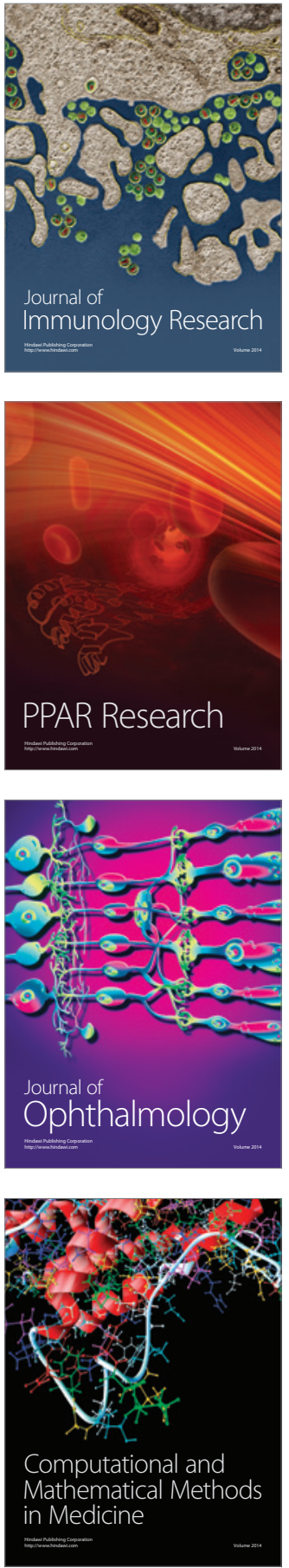

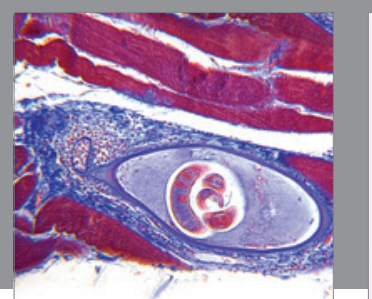

Gastroenterology Research and Practice

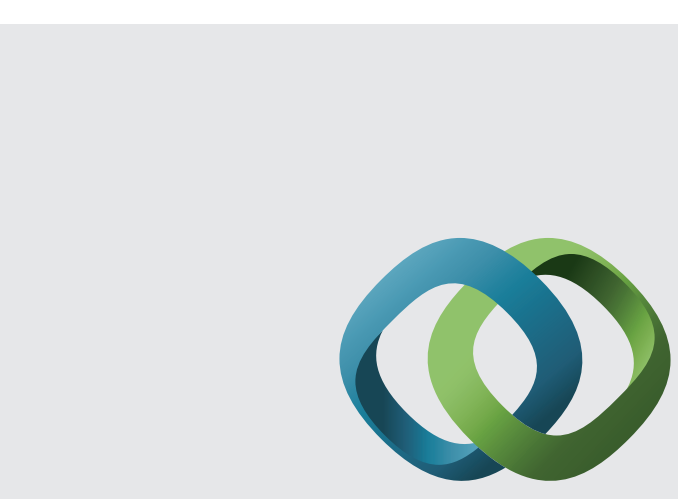

\section{Hindawi}

Submit your manuscripts at

http://www.hindawi.com
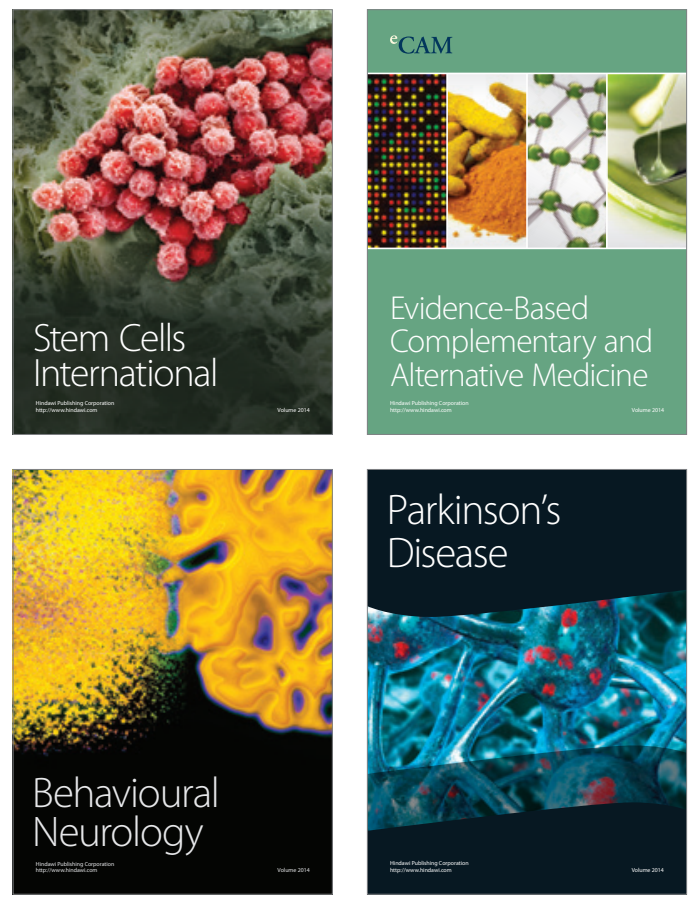
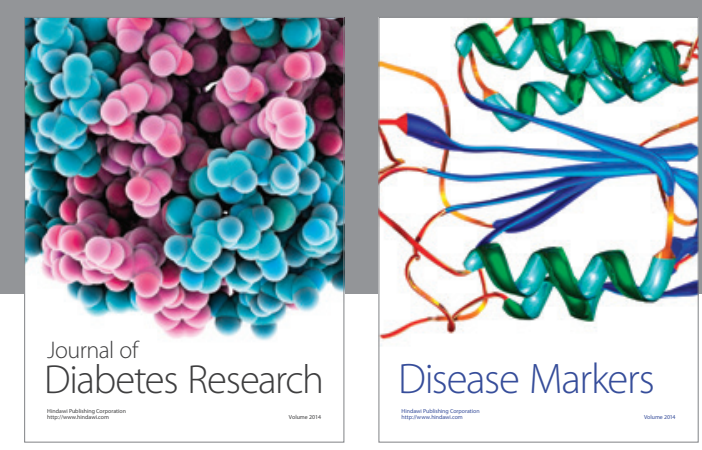

Disease Markers
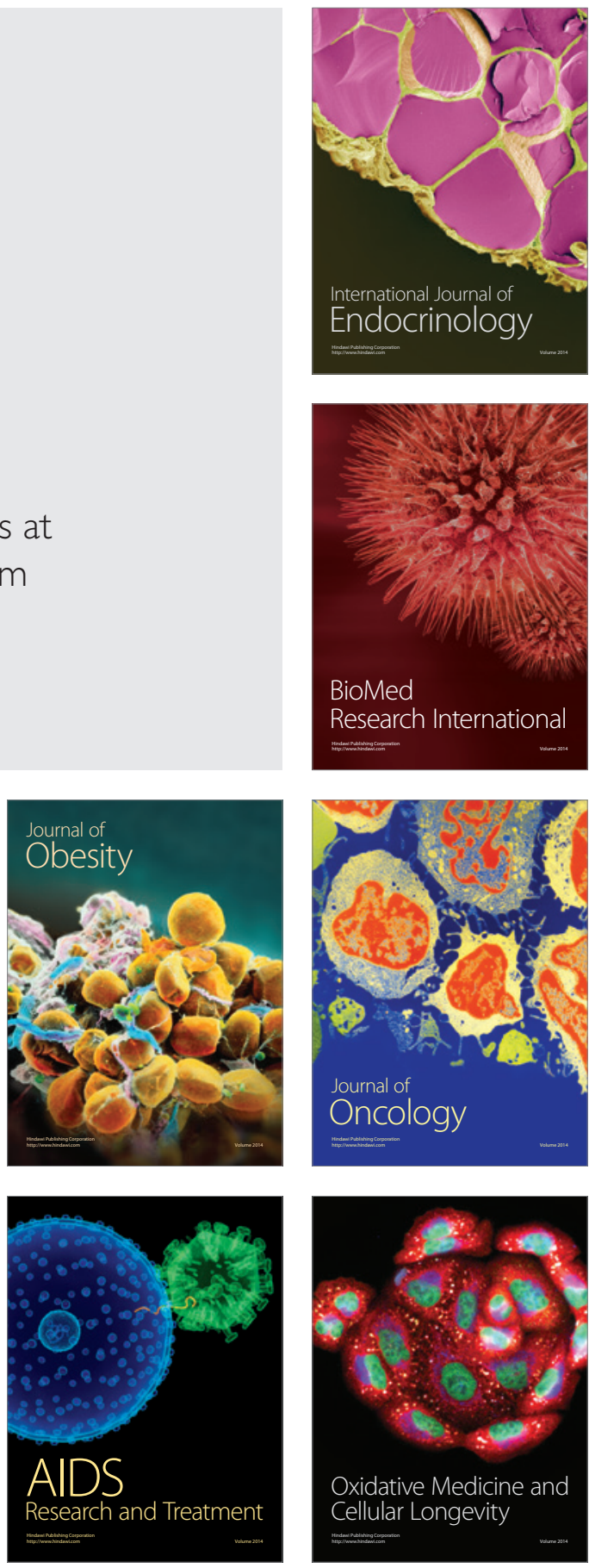